\title{
A Lot-Size Model for Deteriorating Items under Conditions of a One-Time Only Extended Credit Period
}

\begin{abstract}
Nita H. Shah
Department of Mathematics, Gujarat University, Gujarat, Ahmedabad 380 009, India

Correspondence should be addressed to Nita H. Shah, nitahshah@gmail.com

Received 16 July 2009; Accepted 20 January 2010

Academic Editor: Dalibor Froncek

Copyright (C) 2010 Nita H. Shah. This is an open access article distributed under the Creative Commons Attribution License, which permits unrestricted use, distribution, and reproduction in any medium, provided the original work is properly cited.

Now-a-days, the offer of credit period to the customer for settling the account for the units purchased by the supplier is considered to be the most beneficial policy. In this article, an attempt is made to formulate the mathematical model for a customer to determine optimal special cycle time when the supplier offers the special extended credit period for one time only during a special period. A decision policy for a retailer is developed to find optimal special cycle time. The theoretical results and effects of various parameters are studied by appropriate dataset.
\end{abstract}

\section{Introduction}

The most prevailing business strategy is adopted by the supplier to offer credit period of (say) 30 days to settle the account of the retailer. This strategy attracts new customers who consider it to be a type of discount strategy. The interest is not charged if the account is settled within the permissible credit period. However, if the payment is delayed beyond this period, the interest is charged for unsettled account. The retailer can earn the interest by putting generated revenue in an interest-bearing account. Thus, credit period reduces the amount of capital invested in stock, and thereby, reduces retailer's holding cost of stock. When units in inventory are subject to deterioration, the cost of deterioration incurred by the retailer contributes to the total cost of an inventory system.

Goyal [1] developed an economic order quantity (EOQ) model under conditions of permissible delay in payments. Shah [2] and Aggarwal and Jaggi [3] extended Goyal's model for deteriorating items. Jamal et al. [4] generalized the model to allow for shortages. Teng [5] extended Goyal's model by considering the difference between the selling price and the unit price and discussed closed-form solution to the problem analytically. Related research articles are by Shah [6, 7], Hwang and Shinn [8], Jamal et al. [9], Liao et al. [10], Chang et al. [11], 
Sarker et al. [12], Shah [13], Shah et al. [14], Teng et al. [15], Ouyang et al. [16], Shah [17], and many more.

The abovementioned developments assumed that a supplier provides his customer a credit period (say) $M$ for settling the account during the normal period. Soni and Shah [18] derived mathematical model under the assumption that the supplier offers one more credit period (say) $N(N>M)$ to the retailer for settling the account of the purchased goods.

In this paper, an attempt is made to extend the credit period only once during a specified period as a special marketing strategy to motivate the retailer to order larger than usual order quantities. The assumption of Teng [5] that the selling price is higher than the unit purchase cost is considered. The units in inventory are subject to constant rate of deterioration. The necessary and sufficient conditions for the optimal solutions are derived. The algorithm is constructed to find optimal special cycle time. The derived analytical results are illustrated with numerical examples.

\section{Assumptions and Notations}

\subsection{Assumptions}

The proposed mathematical model is derived with the following assumptions.

(i) The annual demand for the product is deterministic and constant over time.

(ii) Lead-time is zero. Shortages are not allowed.

(iii) The replenishment rate is infinite.

(iv) During the credit period, the generated revenue is deposited in an interest-bearing account at the rate of $I e / \$ /$ unit/annum. At the end of the credit period, the retailer pays off for all the sold units, keeps the profit, and pays for the interest charges on the items in the stock at the rate of Ic/\$/unit/annum. In general, Ic > Ie.

(v) The supplier offers a credit period, $M$ for settling accounts during the normal period. However, during festival seasons, the supplier offers extended credit period of $N(N>M)$ to settle the accounts during a given specified period. The customer has a chance to use this offer only once.

(vi) The units in inventory deteriorate at a constant rate (say) $\theta(0 \leq \theta<1)$. The value of $\theta$ is small compared to those of other model parameters. The deteriorated units can neither be repaired nor replaced during a cycle time. The sensitivity analysis in Examples 5.1 and 5.2 is carried out by taking $\theta=0.10$.

\subsection{Notations}

The following notations will be used in building mathematical model.

(i) $R$ : the annual demand.

(ii) $h$ : the inventory holding cost/unit/year excluding interest charges.

(iii) Ic: the interest charges $/ \$$ invested in stock/annum.

(iv) Ie: the interest earned $/ \$$ in a year.

(v) $P$ : the unit selling price of the item/unit.

(vi) $C$ : the unit purchase cost; $P>C$. 
(vii) $A$ : the ordering cost/order.

(viii) $M$ : the usual credit period in settling the account.

(ix) $N$ : the extended credit period in settling the account.

(x) $T_{0}$ : the regular cycle time when the credit period is $M$.

(xi) $T_{s}$ : the special cycle time when the extended credit of $N$-time units is offered.

(xii) $N\left(T_{0}\right)$ : the minimum total annual cost during the period $T_{0}$.

(xiii) $K_{i}\left(T_{s}\right)$ : the total variable cost during the special cycle time $T s$ for case $i$.

\section{Mathematical Model}

Following Goyal [1] and Shah [2], we will derive mathematical models for the following two cases.

Case 1. Let $T_{s} \geq N$, that is, special cycle time is greater than or equal to extended credit period. Under the assumption that the customer can make the use of extended credit offered by the supplier once, the total variable cost during the given specified period is given by

$$
K_{1}\left(T_{s}\right)=A+\frac{(h+C \theta) R}{\theta^{2}}\left\{e^{\theta T_{s}}-\theta T_{s}-1\right\}+\frac{C I c R}{\theta^{2}}\left\{e^{\theta\left(T_{s}-N\right)}-\theta\left(T_{s}-N\right)-1\right\}-\frac{P I e R N^{2}}{2} .
$$

The total cost during cycle time under normal condition is given by $T_{S} N\left(T_{0}\right)$. Therefore, the net cost of the system as a result of changing the payment scenario during the given specified time is given by $Z_{1}\left(T_{s}\right)=K_{1}\left(T_{s}\right)-T_{s} N\left(T_{0}\right)$. To obtain minimum value of $Z_{1}\left(T_{s}\right)$, the necessary condition is $d Z_{1}\left(T_{s}\right) / d T_{s}=0$, that is,

$$
\frac{(h+C \theta) R}{\theta}\left\{e^{\theta T_{s}}-1\right\}+\frac{C I c R}{\theta}\left\{e^{\theta\left(T_{s}-N\right)}-1\right\}-N\left(T_{0}\right)=0,
$$

and sufficient condition is

$$
\frac{d^{2} Z_{1}\left(T_{s}\right)}{d T_{s}^{2}}=\left\{h+C \theta+C I c e^{-\theta N}\right\} R e^{\theta T_{s}}>0 .
$$

We need to solve (3.2) for $T_{s}=T_{s 1}$ by suitable numerical method. Assuming $\theta$ to be very small, we take series approximation of exponential up to $\theta$ (neglecting $\theta^{2}$ and higher powers). We get

$$
\frac{(h+C I c) \theta T_{s}^{2}}{2}+\{h+C \theta+C I c(1-\theta N)\} T_{s}-C I c N+\frac{C I c \theta N^{2}}{2}-\frac{N\left(T_{0}\right)}{R}=0,
$$


which gives

$$
\begin{aligned}
T_{s}= & T_{s 1} \times \\
& \frac{-\{h+C \theta+C I c(1-\theta N)\}}{(h+C I c) \theta} \\
& \frac{+\sqrt{\{h+C \theta+C I c(1-\theta N)\}-2(h+C I c) \theta\left(-C I c N+\left(C I c \theta N^{2} / 2\right)-\left(N\left(T_{0}\right) / R\right)\right)}}{(h+C I c) \theta},
\end{aligned}
$$

To ensure that $T_{s 1}>N$, we substitute (3.5) into inequality $T_{s 1}>N$ and obtain that

$$
N\left(T_{0}\right)>\frac{\left\{2 h^{2}+2 C I c h+2 C^{2} I c \theta+C I c h \theta N+h^{2} \theta N+2 C h \theta\right\} N R}{2(h+C I c)} .
$$

Case $2\left(T_{S}<N\right)$. Following Shah [2], the total variable cost during the given specified period is

$$
K_{2}\left(T_{s}\right)=A+\frac{(h+C \theta) R}{\theta^{2}}\left\{e^{\theta T_{s}}-\theta T_{s}-1\right\}+P \operatorname{PIR} T_{s}\left\{N-\frac{T_{s}}{2}\right\} .
$$

Arguing as above, the net cost incurred during the given specified period is $Z_{2}\left(T_{s}\right)=K_{2}\left(T_{S}\right)$ $T_{S} N\left(T_{0}\right)$. Under series approximation, $T_{S}$ is given by

$$
T_{s}=\frac{-(h+C \theta+P I e)+\sqrt{(h+C \theta+P I e)^{2}+2 h \theta\left(P I e N+\left(N\left(T_{0}\right) / R\right)\right)}}{h \theta},
$$

and sufficient condition is

$$
\frac{d^{2} Z_{2}\left(T_{s}\right)}{d T_{s}^{2}}=(h+C \theta) R e^{\theta T_{s}}+\text { PIeR }>0 .
$$

Substituting (3.8) into inequality $T_{S}<N$, we get

$$
N\left(T_{0}\right)<R \frac{N\{N \theta(h+C \theta)+2(h+C \theta-P I e)\}+2 P I e N}{2} .
$$

From (3.5), (3.6), (3.8), and (3.10), we have the following postulates. 
Postulate 1.

(1) If (3.6) holds, then the optimal cycle time $T_{s 1}$ for special credit period is given by (3.5).

(2) If (3.10) holds, then the optimal cycle time $T_{s 2}$ for special credit period is given by (3.8).

(3) If equality holds in (3.6) or (3.10), then the optimal cycle time is $N$ for special credit period.

Proof. It follows from above discussions.

Using results of Shah [2] and above theorem, we have the following postulate.

Postulate 2. Let

$$
\begin{gathered}
\Delta_{1}=R(h+C \theta+P I e) M^{2}, \\
\Delta_{2}=R(h+C \theta) N, \\
T_{01}=\sqrt{\frac{2 A+M^{2} R(C I c-P I e)}{(h+C \theta+C I c) R},} \\
T_{02}=\sqrt{\frac{2 A}{(h+C \theta+P I e) R}} .
\end{gathered}
$$

(1) If $2 A>\Delta_{1}$ and

(i) $N\left(T_{01}\right)>\Delta_{2}$, then optimal cycle time is $T_{s 1}$ for extended credit period.

(ii) $N\left(T_{01}\right)<\Delta_{2}$, then optimal cycle time is $T_{s 2}$ for extended credit period.

(iii) $N\left(T_{01}\right)=\Delta_{2}$, then optimal cycle time is $N$, the extended credit period.

(2) If $2 A=\Delta_{1}$ and

(i) $N(M)>\Delta_{2}$, then optimal cycle time is $T_{s 1}$ for extended credit period.

(ii) $N(M)<\Delta_{2}$, then optimal cycle time is $T_{s 2}$ for extended credit period.

(iii) $N(M)=\Delta_{2}$, then optimal cycle time is $N$, the extended credit period.

(3) If $2 A<\Delta_{1}$ and

(i) $N\left(T_{02}\right)>\Delta_{2}$ then optimal cycle time is $T_{s 1}$ for extended credit period.

(ii) $N\left(T_{02}\right)<\Delta_{2}$ then optimal cycle time is $T_{s 2}$ for extended credit period.

(iii) $N\left(T_{02}\right)=\Delta_{2}$ then optimal cycle time is $N$; the extended credit period.

Using Shah [2], the minimum annual cost is

$$
\begin{gathered}
N\left(T_{01}\right)=\frac{A}{T_{01}}+\frac{(h+C \theta) R}{\theta^{2} T_{01}}\left\{e^{\theta T_{01}}-\theta T_{01}-1\right\}+\frac{C I c R}{\theta^{2} T_{01}}\left\{e^{\left(\theta T_{01}-M\right)}-\theta\left(T_{01}-M\right)-1\right\}-\frac{\text { PIeRM } M^{2}}{2 T_{01}}, \\
N\left(T_{02}\right)=\frac{A}{T_{02}}+\frac{(h+C \theta) R}{\theta^{2} T_{02}}\left\{e^{\theta T_{02}}-\theta T_{02}-1\right\}-\operatorname{PIeR}\left\{M-\frac{T_{02}}{2}\right\} .
\end{gathered}
$$


Table 1: Optimal solution for different ordering costs.

\begin{tabular}{cccccc}
\hline$A$ & $T_{0}$ & $N\left(T_{0}\right)$ & $T_{s}$ & $K_{i}\left(T_{s}\right)$ & $Z_{i}\left(T_{s}\right)$ \\
\hline 10 & $T_{02}=0.0354$ & $N\left(T_{02}\right)=382.81$ & $T_{s 2}=0.0462$ & $K_{2}\left(T_{s 2}\right)=9.73$ & -7.96 \\
20 & $T_{01}=0.0491$ & $N\left(T_{01}\right)=622.48$ & $T_{s 1}=0.0594$ & $K_{2}\left(T_{s 2}\right)=26.01$ & -10.97 \\
30 & $T_{01}=0.0605$ & $N\left(T_{01}\right)=805.07$ & $T_{s 1}=0.0707$ & $K_{2}\left(T_{s 2}\right)=44.14$ & -12.97 \\
40 & $T_{01}=0.0701$ & $N\left(T_{01}\right)=958.40$ & $T_{s 1}=0.0803$ & $K_{2}\left(T_{s 2}\right)=62.57$ & -14.39 \\
50 & $T_{01}=0.0785$ & $N\left(T_{01}\right)=1093.23$ & $T_{s 1}=0.0886$ & $K_{2}\left(T_{s 2}\right)=81.19$ & -15.67 \\
\hline
\end{tabular}

\section{Algorithms}

Step 1. If $2 A>\Delta_{1}$, then go to Algorithm A.

Step 2. If $2 A=\Delta_{1}$, then go to Algorithm B.

Step 3. If $2 A<\Delta_{1}$, then go to Algorithm C.

Algorithm A. The steps are as follows.

(A.0) Compute $T_{01}$ using (3.12) and $N\left(T_{01}\right)$ using (3.14).

(A.1) If $N\left(T_{01}\right)>\Delta_{2}$, then optimal solution is $\left(T_{s 1}, K_{1}\left(T_{s 1}\right)\right)$.

(A.2) If $N\left(T_{01}\right)<\Delta_{2}$, then optimal solution is $\left(T_{s 2}, K_{1}\left(T_{s 2}\right)\right)$.

(A.3) If $N\left(T_{01}\right)=\Delta_{2}$, then optimal solution is $\left(N, K_{1}(N)=K_{2}(N)\right)$.

Algorithm B. The steps are as follows.

(B.0) Set $T=M$ and calculate

$$
N(M)=\frac{A}{M}+\frac{(h+C \theta) R}{\theta^{2} M}\left\{e^{\theta M}-\theta M-1\right\}-\frac{P I e R M}{2} .
$$

(B.1) If $N(M)>\Delta_{2}$, then optimal solution is $\left(T_{s 1}, K_{1}\left(T_{s 1}\right)\right)$.

(B.2) If $N(M)<\Delta_{2}$, then optimal solution is $\left(T_{s 2}, K_{1}\left(T_{s 2}\right)\right)$.

(B.3) If $N(M)=\Delta_{2}$, then optimal solution is $\left(N, K_{1}(N)=K_{2}(N)\right)$.

Algorithm C. The steps are as follows.

(C.0) Compute $T_{02}$ using (3.13) and $N\left(T_{02}\right)$ using (3.15).

(C.1) If $N\left(T_{02}\right)>\Delta_{2}$, then optimal solution is $\left(T_{s 1}, K_{1}\left(T_{s 1}\right)\right)$.

(C.2) If $N\left(T_{02}\right)<\Delta_{2}$, then optimal solution is $\left(T_{s 2}, K_{1}\left(T_{s 2}\right)\right)$.

(C.3) If $N\left(T_{02}\right)=\Delta_{2}$, then optimal solution is $\left(N, K_{1}(N)=K_{2}(N)\right)$. 
Table 2: Optimal solution for extended credit period.

\begin{tabular}{lcccr}
\hline$N$ & $\Delta_{2}$ & $T_{s}$ & $K_{i}\left(T_{s}\right)$ & $Z_{i}\left(T_{s}\right)$ \\
\hline $30 / 365$ & 493.15 & $T_{s 2}=0.0963$ & $K_{2}\left(T_{s 2}\right)=49.97$ & -8.53 \\
$45 / 365$ & 739.73 & $T_{s 1}=0.1065$ & $K_{2}\left(T_{s 2}\right)=46.17$ & -18.53 \\
$60 / 365$ & 986.30 & $T_{s 1}=0.1167$ & $K_{2}\left(T_{s 2}\right)=40.84$ & -30.06 \\
$75 / 365$ & 1232.88 & $T_{s 1}=0.1268$ & $K_{2}\left(T_{s 2}\right)=33.96$ & -43.07 \\
\hline
\end{tabular}

Table 3: Effect of deterioration of units on optimal solution.

\begin{tabular}{lccccccr}
\hline$\Theta$ & $\Delta_{1}$ & $\Delta_{2}$ & $T_{01}$ & $N\left(T_{01}\right)$ & $T_{s 1}$ & $K_{i}\left(T_{s 1}\right)$ & $Z_{i}\left(T_{s 1}\right)$ \\
\hline 0.10 & 14.19 & 493.15 & 0.0861 & 607.50 & 0.0963 & 49.97 & -8.53 \\
0.15 & 15.88 & 575.34 & 0.0812 & 649.70 & 0.0902 & 50.55 & -8.05 \\
0.20 & 17.56 & 657.53 & 0.0770 & 689.66 & 0.0851 & 51.04 & -7.65 \\
0.25 & 19.25 & 739.73 & 0.0734 & 747.70 & 0.0809 & 51.47 & -7.40 \\
\hline
\end{tabular}

\section{Numerical Examples}

Example 5.1. Consider the data

$$
[R, h, I c, I e, C, P, M, N, \theta]=\left[2000,4,0.10,0.08,20,30, \frac{15}{365}, \frac{30}{365}, 0.10\right]
$$

in appropriate units. Then $\Delta_{1}=28.37$ and $\Delta_{2}=986.30$. Using The Algorithms A-C., let us tabulate computational results for $A=10,20,30,40$, and 50 in Table 1.

It is observed that increase in ordering cost increases $T_{0}, N\left(T_{0}\right), T_{s}$, and $K_{i}\left(T_{s}\right)$ but decreases the net cost $Z_{i}\left(T_{s}\right)$.

Example 5.2. Consider the data

$$
[R, h, I c, I e, C, P, A, M, \theta]=\left[1000,4,0.10,0.08,20,30,30, \frac{15}{365}, 0.10\right]
$$

in appropriate units. Then $2 A=60>\Delta_{1}=14.19$. Using Algorithm A, we get $T_{0}=T_{01}=$ 0.0861 and $N\left(T_{01}\right)=607.50$. Let us study effect of extended credit period $N$ on the decision variables in Table 2.

It is observed that increase in extended credit period increases $\Delta_{2}$ and special cycle time but decreases in the total annual cost of an inventory system and net cost.

Example 5.3. Consider the data

$$
[R, h, I c, I e, C, P, A, M, N]=\left[1000,4,0.10,0.08,20,30,30, \frac{15}{365}, \frac{30}{365}\right]
$$

in appropriate units. In Table 3, we study the effect of deterioration on decision variables. 
Increase in deterioration of units in inventory system lowers normal cycle time, special cycle time, net cost, and increase in total annual cost of an inventory system and special credit period policy.

\section{Conclusions}

In this article, we extended classical EOQ model for a retailer when units in inventory are subject to deterioration at a constant rate and supplier offers only one-time extended credit period to settle retailer's account. Under series approximation of exponential term, a closedform solution of optimal cycle time is obtained. The algorithms are provided for determining optimal policy.

\section{Acknowledgment}

The author is thankful to reviewer for his suggestions to improve the research article.

\section{References}

[1] S. K. Goyal, "Economic ordering quantity under conditions of permissible delay in payments," Journal of the Operational Research Society, vol. 36, pp. 335-338, 1985.

[2] N. H. Shah, "A lot-size model for exponentially decaying inventory when delay in payments is permissible," Cahiers du Centre D'Etudes de Recherche Operationnell, vol. 35, pp. 1-9, 1993.

[3] S. P. Aggarwal and C. K. Jaggi, "Ordering policies of deteriorating items under permissible delay in payments," Journal of the Operational Research Society, vol. 46, pp. 658-662, 1995.

[4] A. M. M. Jamal, B. R. Sarker, and S. Wang, "An ordering policy for deteriorating items with allowable shortage and permissible delay in payment," Journal of the Operational Research Society, vol. 48, pp. 826-833, 1997.

[5] J.-T. Teng, "On the economic order quantity under conditions of permissible delay in payments," Journal of the Operational Research Society, vol. 53, pp. 915-918, 2002.

[6] N. H. Shah, "A probabilistic order level system when delay in payments is permissible," Journal of the Korean Operations Research and Management Science, vol. 18, no. 2, pp. 175-183, 1993.

[7] N. H. Shah, "Probabilistic time scheduling model for exponentially decaying inventory when delay in payments is permissible," International Journal of Production Economics, vol. 32, pp. 77-82, 1993.

[8] H. Hwang and S. W. Shinn, "Retailer's pricing and lot-sizing policy for exponentially deteriorating products under the condition of permissible delay in payments," Computers and Operations Research, vol. 24, pp. 539-547, 1997.

[9] A. M. M. Jamal, B. R. Sarker, and S. Wang, "Optimal payment time for a retailer under permitted delay of payments by the wholesaler," International Journal of Production Economics, vol. 66, pp. 59-66, 2000.

[10] H. C. Liao, C. H. Tsai, and C. T. Su, “An inventory model with deteriorating items under inflation when a delay in payments is permissible," International Journal of Production Economics, vol. 63, pp. 207-214, 2000.

[11] C.-T. Chang, L.-Y. Ouyang, and J.-T. Teng, “An EOQ model for deteriorating items under supplier credits linked to ordering quantity," Applied Mathematical Modeling, vol. 27, pp. 983-996, 2003.

[12] B. R. Sarker, A. M. M. Jamal, and S. Wang, "Optimal payment time under permissible delay for production with deterioration," Production Planning E Control, vol. 11, pp. 380-390, 2001.

[13] N. H. Shah, "Probabilistic order level system when items in inventory deteriorate and delay in payments is permissible," Asia-Pacific Journal of Operational Research, vol. 21, no. 3, pp. 319-331, 2004.

[14] B. J. Shah, N. H. Shah, and Y. K. Shah, "An order-level lot-size model with stock dependent demand for time dependent deterioration under permissible delay in payments," Far East Journal of Theoretical Statistics, vol. 12, no. 2, pp. 201-220, 2004.

[15] J.-T. Teng, C.-T. Chang, and S. K. Goyal, "Optimal pricing and ordering policy under permissible delay in payments," International Journal of Production Economics, vol. 97, no. 2, pp. 121-129, 2005. 
[16] L.-Y. Ouyang, J.-T. Teng, K.-W. Chuang, and B.-R. Chuang, "Optimal inventory policy with non instantaneous receipt under trade credit," International Journal of Production Economics, vol. 98, no. 3, pp. 290-300, 2005.

[17] N. H. Shah, "Inventory model for deteriorating items and time value of money for a finite time horizon under the permissible delay in payments," International Journal of Systems Science, vol. 37, no. 1, pp. 9-15, 2006.

[18] H. Soni and N. H. Shah, "Optimal ordering policies for exponentially deteriorating items under scenario of progressive credit period," Far East Journal of Theoretical Statistics, vol. 17, no. 1, pp. 117,2005 . 


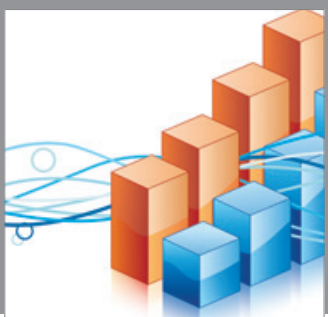

Advances in

Operations Research

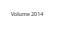

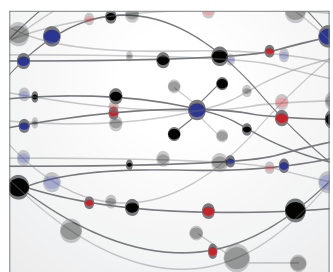

\section{The Scientific} World Journal
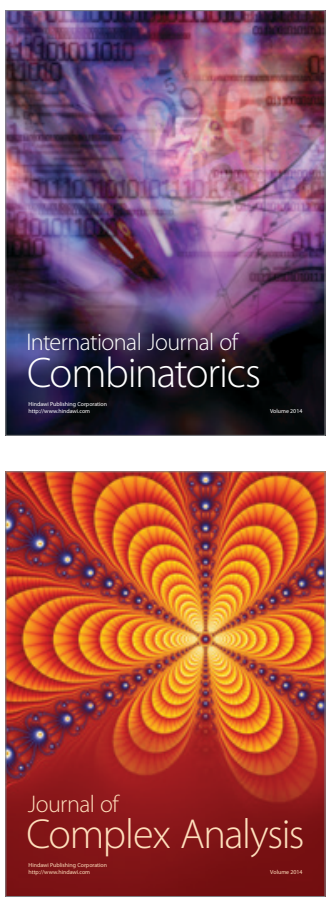

International Journal of

Mathematics and

Mathematical

Sciences
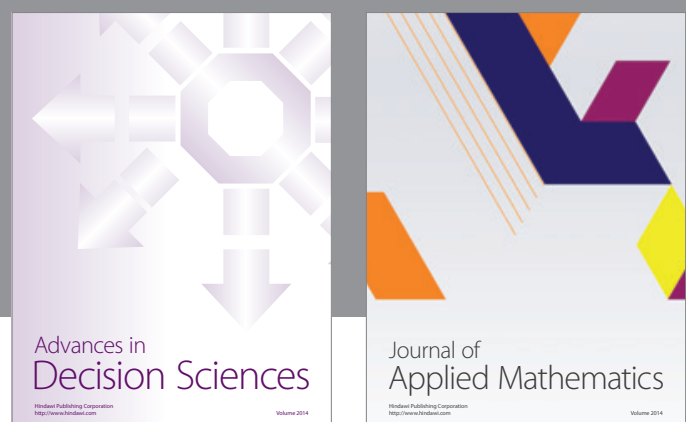

Journal of

Applied Mathematics
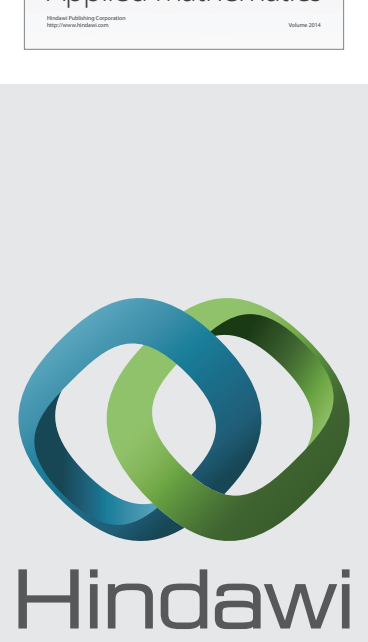

Submit your manuscripts at http://www.hindawi.com
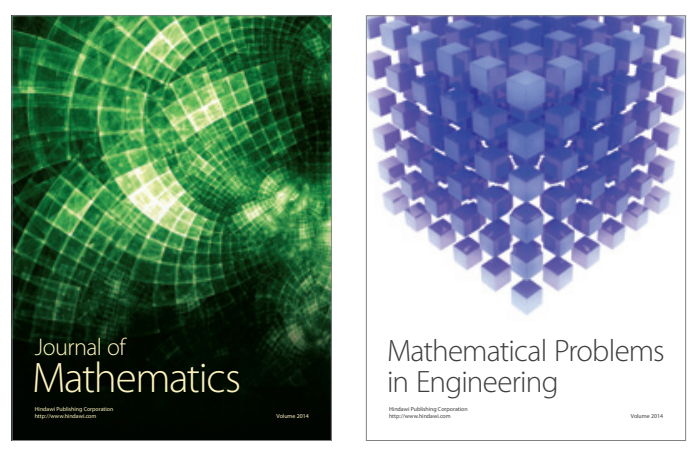

Mathematical Problems in Engineering
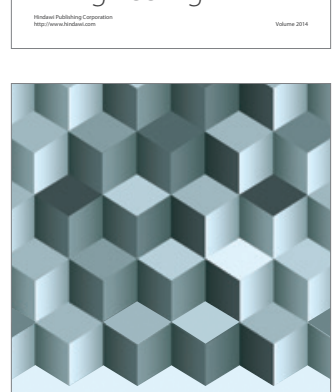

Journal of

Function Spaces
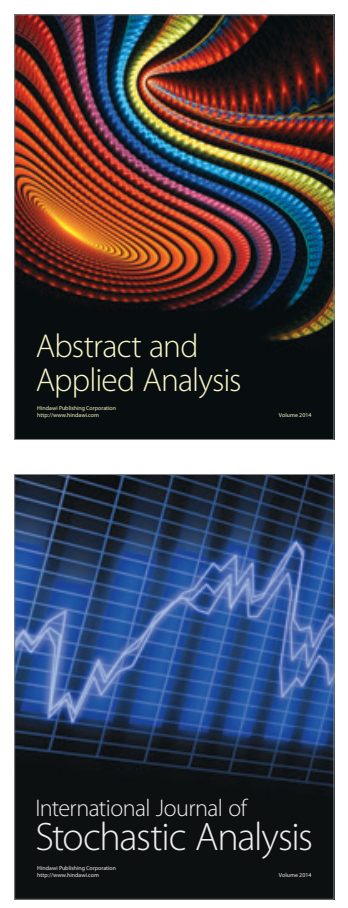

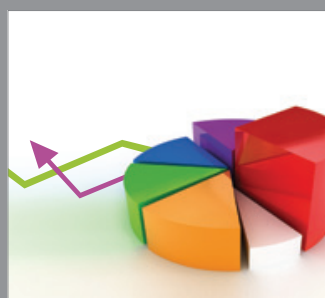

ournal of

Probability and Statistics

Promensencen
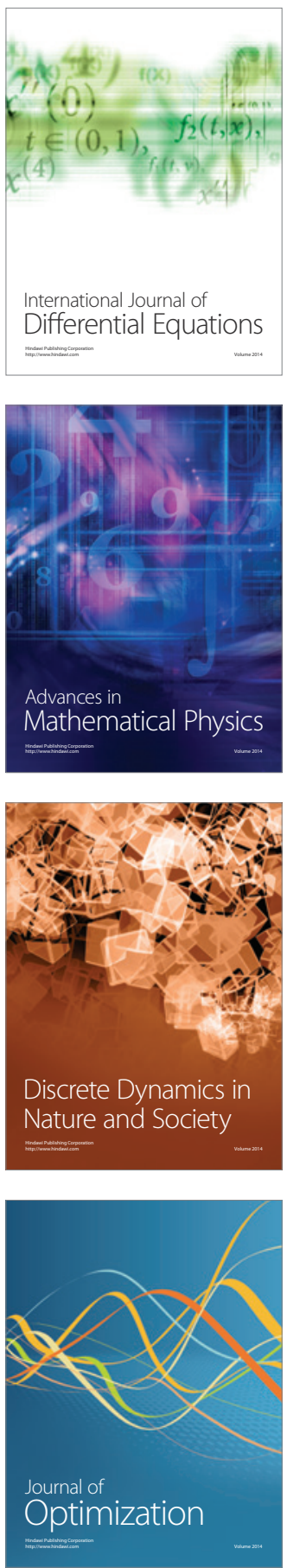